\title{
Lipid II Binding and Transmembrane Properties of Various Antimicrobial Lanthipeptides
}

Rudramani Pokhrel ${ }^{1}$, Nisha Bhattarai ${ }^{1}$, Prabin Baral ${ }^{1}$, Bernard S. Gerstman ${ }^{1,2}$, Jae H. Park ${ }^{3}$, Martin Handfield ${ }^{3}$, and Prem P. Chapagain ${ }^{1,2 *}$

${ }^{1}$ Department of Physics and ${ }^{2}$ Biomolecular Sciences Institute, Florida International University, Miami, FL 33199 USA.

${ }^{3}$ Oragenics Inc., Alachua, FL, USA.

*Email: chapagap@,fiu.edu

\section{Supporting Information}
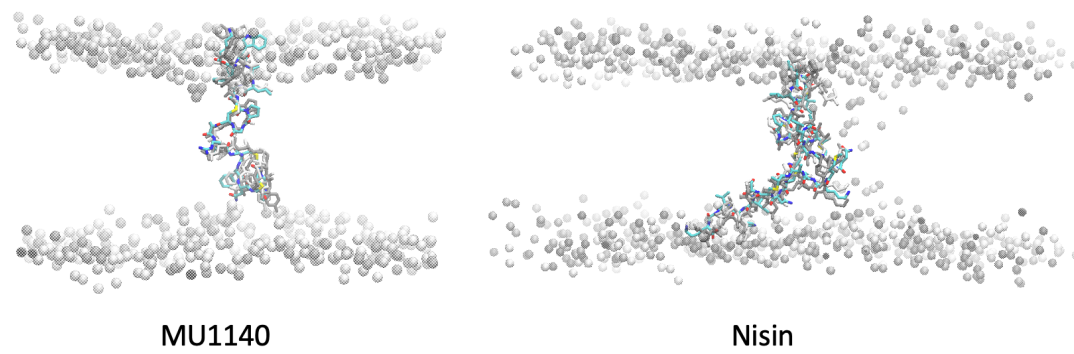

Nisin

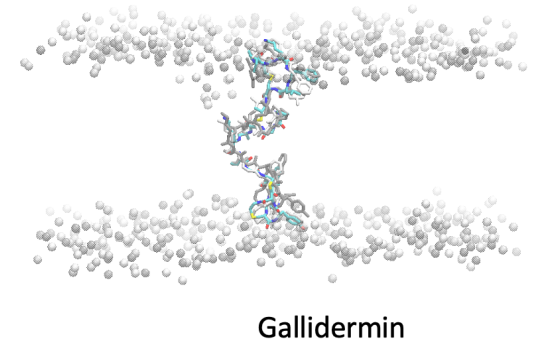

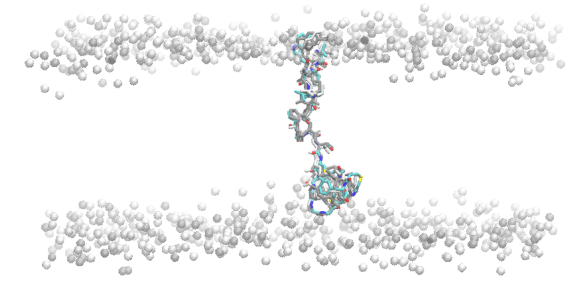

NAl107

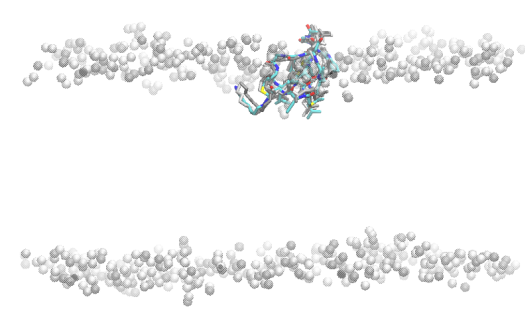

NVB302

Figure S1. Representative structures of the peptides in the lipid bilayer obtained from the cluster analysis of the last $300 \mathrm{~ns}$ of $1 \mu$ s production run. Ten structures from different clusters are colored from Black-Gray-White transitions. The $\mathrm{P}$ atoms of the lipids in the upper and lower leaflets of the membranes are shown. 


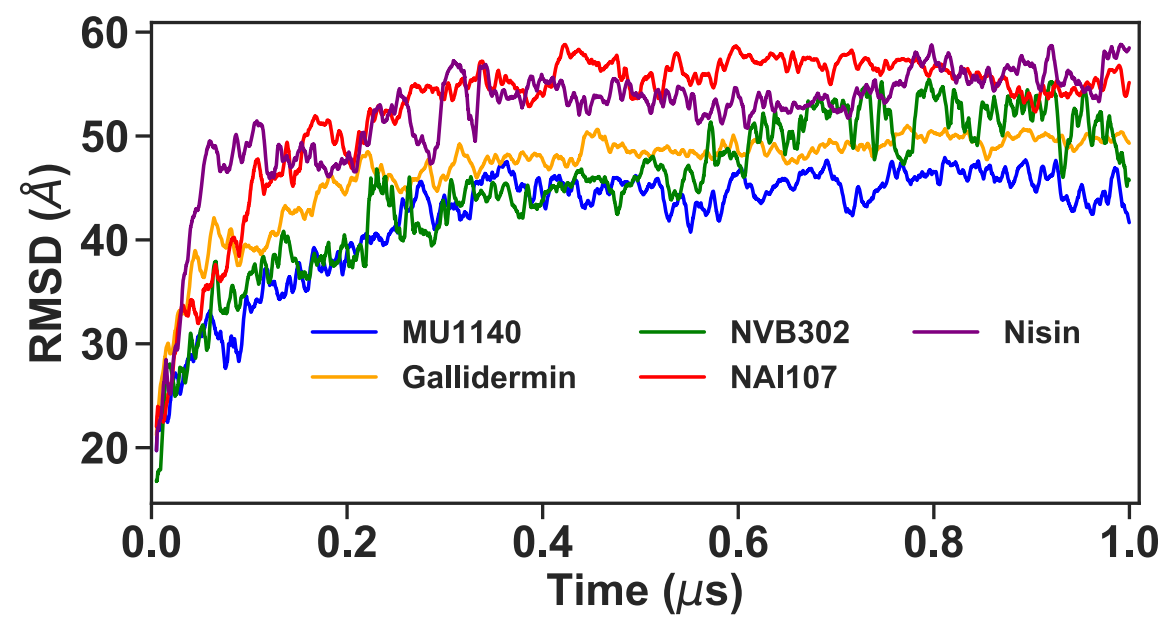

Figure S2. Time evolution of the root mean squared deviation (RMSD) of the membrane for the simulated systems.

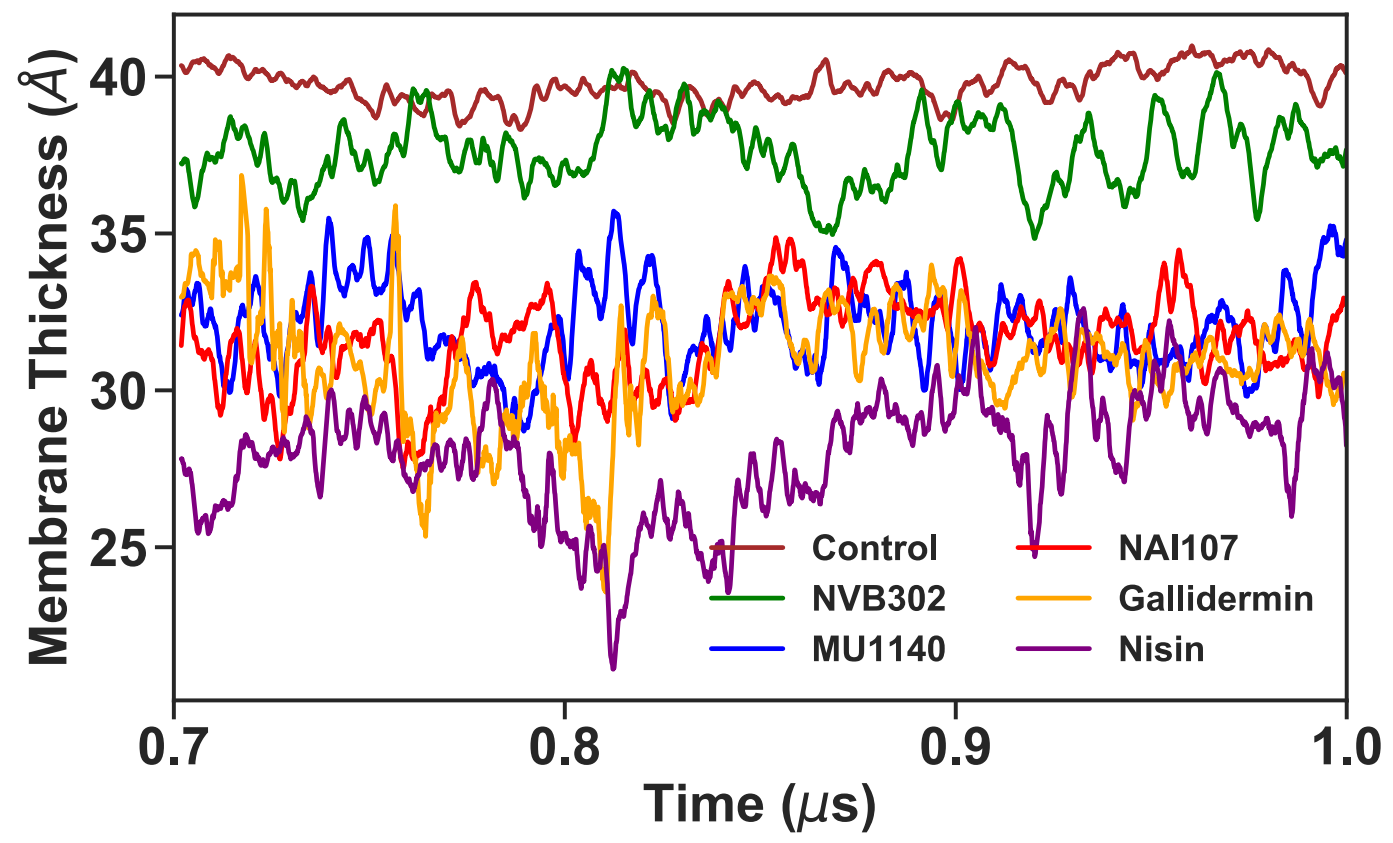

Figure S3. Time evolution of the membrane thickness within $12 \AA$ of peptides, showing relative stabilities. 


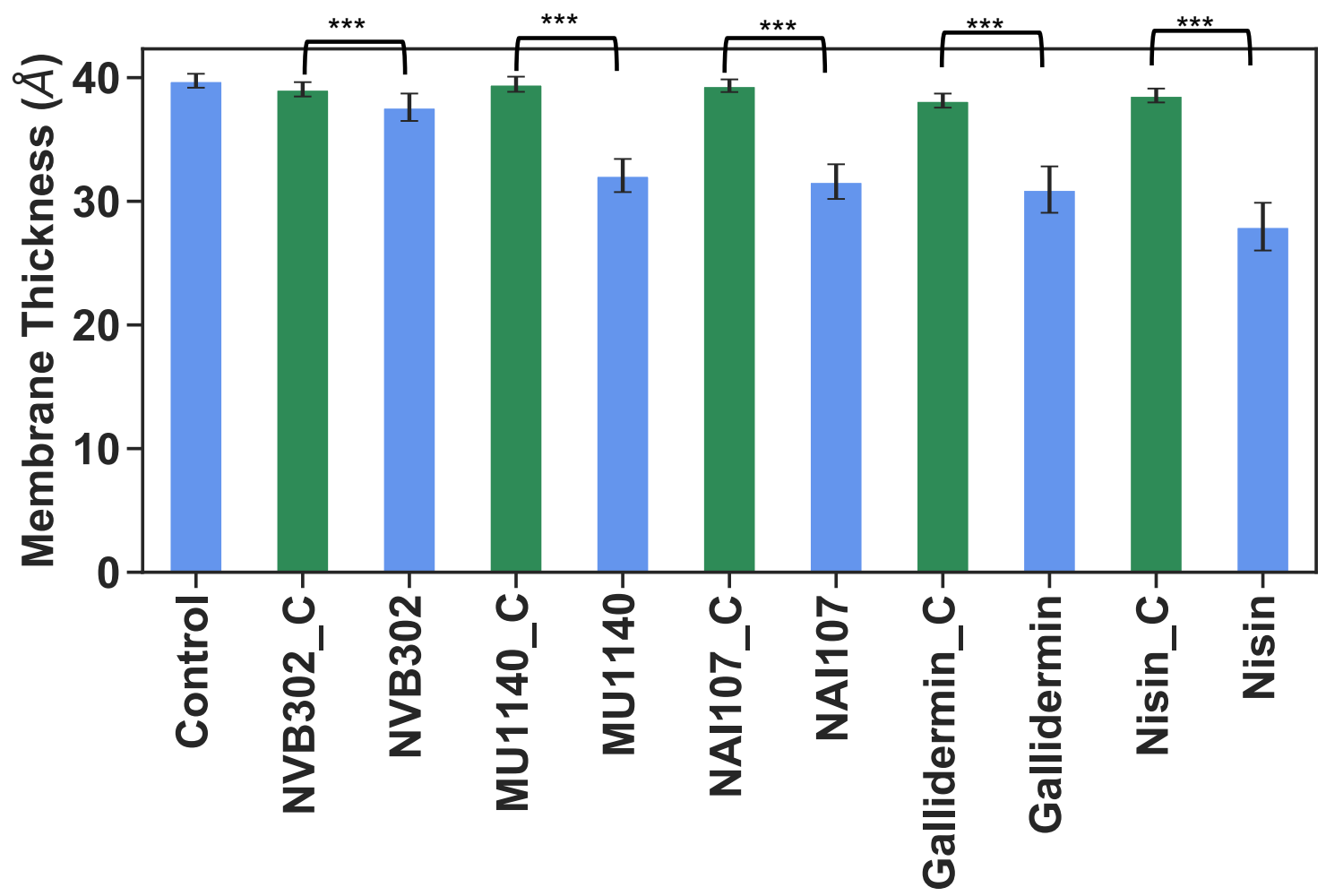

Figure S4. Membrane thickness: bar graph for the distance between the phosphate atoms within $12 \AA$ of peptides (blue bar) and outside $12 \AA$ of peptides (green bar, control). The stars indicate that the mean values are significantly different $(* * * \mathrm{p}<0.001)$. 
Table S1. Details of the system set-up.

\begin{tabular}{|c|c|c|c|c|c|c|}
\hline System & Total no. & \multicolumn{2}{|c|}{ Lipid Number } & No. of water & \multicolumn{2}{|c|}{ Ions } \\
\cline { 7 - 8 } & of atoms & POPG & POPE & molecules & Na & Cl \\
\hline MU1140 & 48813 & 152 & 50 & 7531 & 171 & 18 \\
\hline Nisin & 80315 & 237 & 80 & 13092 & 270 & 33 \\
\hline Gallidermin & 65484 & 180 & 60 & 11471 & 210 & 29 \\
\hline NVB302 & 61758 & 183 & 61 & 10067 & 212 & 25 \\
\hline NAI107 & 71696 & 240 & 80 & 10155 & 268 & 25 \\
\hline
\end{tabular}

Table S2. Percentage contribution of the peptide backbone (NH, CO) and the side chain hydrogen bonding with water during the last $300 \mathrm{~ns}$ of the simulation.

\begin{tabular}{|l|c|c|c|}
\hline \multirow{2}{*}{$\begin{array}{c}\text { Lantibiotic } \\
\text { variants }\end{array}$} & \multicolumn{3}{|c|}{ \% H-bond contribution with water } \\
\cline { 2 - 4 } & $\mathrm{NH}$ & $\mathrm{CO}$ & Sidechain \\
\hline Gallidermin & 43 & 55 & 2 \\
\hline NAI107 & 35 & 47 & 18 \\
\hline MU1140 & 29 & 53 & 18 \\
\hline NVB302 & 26 & 53 & 21 \\
\hline Nisin & 28 & 52 & 20 \\
\hline
\end{tabular}



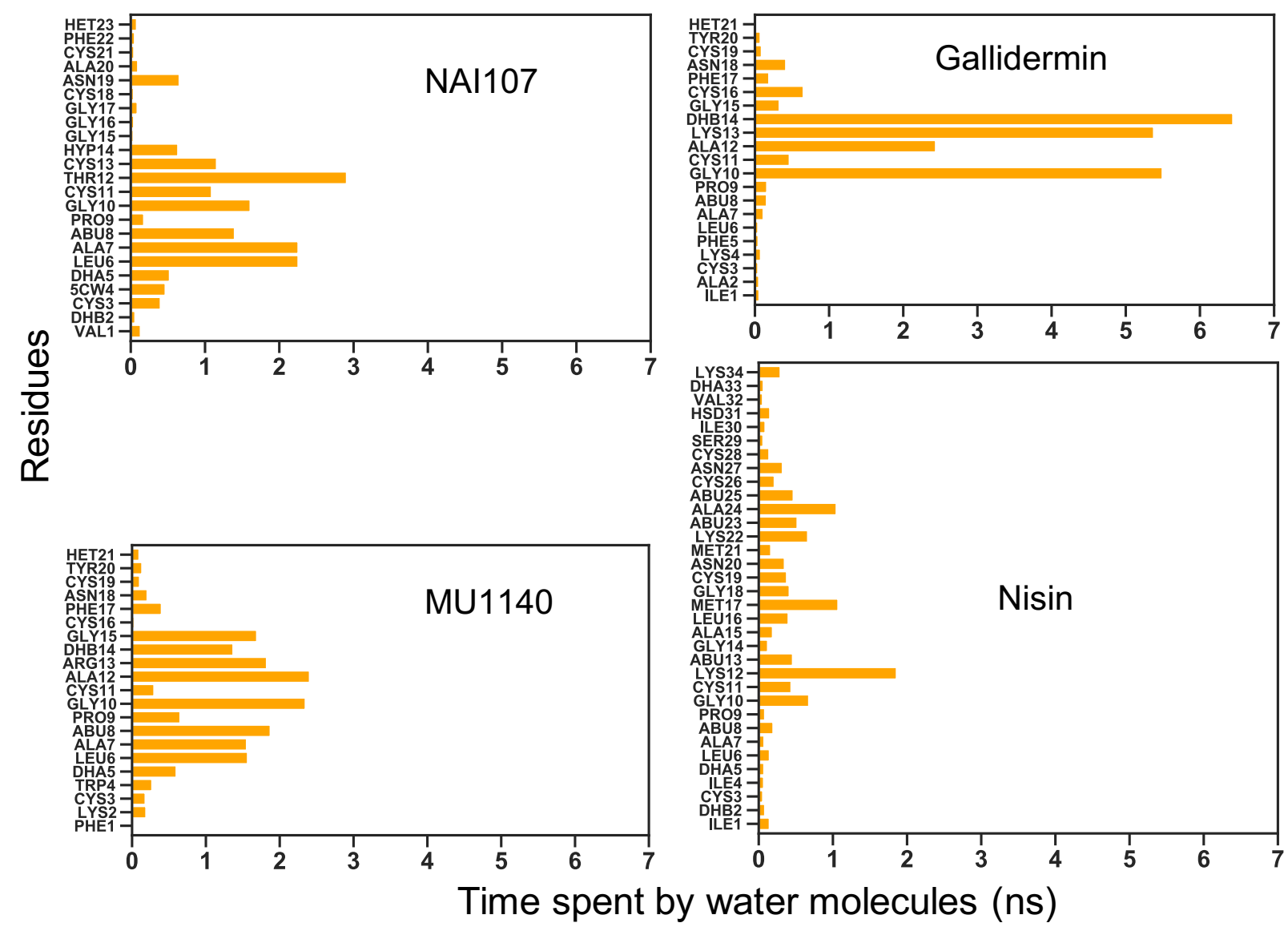

Figure S5. The average time spent (i.e. the residence time) by the water molecules near (within $2.5 \AA$ ) each residue for the last 300 ns of the trajectory for different variants. 